\title{
Frequency of Cerebrovascular Lesions in Leprosaria
}

\author{
MUTSUHIRO FURUTA \\ (Kyoto National Hospital Leprosy Research Laboratory Kyoto University) \\ MOTOAKI OZAKI \\ (National Leprosarium Nagashima Aisei-en) \\ NoBUo HARADA, SHIGEO MATSUMOTO \\ (National Leprosarium Oku Komyo-en) \\ EIJI NAGAO, KAZUKo SUGIYAMA, TAKESHI OGASAWARA \\ AND Yoshiko MATSUMOTO \\ (National Leprosarium Ohshima Seisho-en)
}

Cerebrovascular diseases, especially cerebral hemorrhage, have been thought the most frequent cause of death in Japan. The Ministry of Health and Welfare has reported that cerebrovascular diseases have been the top of the cause of death in Japan since 1951. Pathologists, however, do not have experienced so many autopsy cases who died of cerebrovascular diseases. Then, we investigated the cause of death in two leprosaria and compared it with informations from the Ministry of Health and Welfare.

One hundred and twenty seven patients died in Komyo-en Leprosarium between 1962, January, and 1971, June. Autopsy was done on 110 cases. The average age was 62.5 years old. Malignant neoplasms (33 cases) were more frequent than cerebrovascular diseases (hemorrhage : 9 cases, softening: 3, microscopic hemorrhage : 11). The major direct cause of death was bronchopneumonia. Investigation of the death certificates in Seisho-en Leprosarium for the years 1967-1976 also revealed that cerebrovascular diseases were not the major cause of death. These results are different from informations of the cause of death in Japan published by the Ministry of Health and Welfare. This discrepancy probably comes from inaccurate description of the death certificates and low autopsy rate in this country. 


\section{はたして脳出血は多いのか}

一わたくしたちの療養所の経験から—

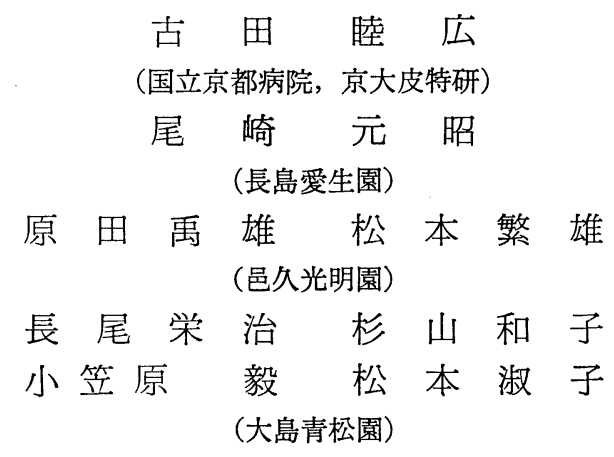

（受付 1972年10月14日）

1977年 6 月, 厚生省は1976年の「人口動態の概況」を 発表した。これによると，日本人の平均寿命は男子が 72.15 歳, 女子は77.35歳となり, わが国は世界でも最高 の長寿国のひとつとなったという1。 また，死因の第一 位は男女ともに脳血管疾患であり，その比率は男 23.8 $\%$,女 $26.0 \%$ で, 死亡者の約 $1 / 4$ は脳血管疾患により死 亡しているという2。日本人の死因の第一位は1951年以 来脳血管疾患とされ3)，とりわけ脳出血が多いことはよ く知られた事実とされてきた。

しかし, 病理解剖に従事するものにとっては, もっと も多いのは悪性腫瘍の症例で, 脳血管疾患の症例にあう ことは比較的少い。さいわいなことに, 邑久光明園では 1962年から1971年の間に剖検率 $86.6 \%$ といら高率で, 病 理解剖が扢こなわれてきた。その結果も，やはり悪性腫 瘍がもっとも多いことをしめした4)。そこで，大島青松 園の1967年から1976年の死因調查をおこない，光明園の 病理解剖の結果と比較し, らい療養所での脳血管疾患の 発生状況を調查した。

\section{症 例}

邑久光明園：1962年 1 月から1971年 6 月までに解剖さ れた110例の主要疾患のまとめを Table 1にしめした。 この期間の全死亡数は 129 である。のうち，2 例の非 らいの症例を除き, 剖検率は $86.6 \%$ に達する。剖検を受 けなかった症例は, 変死・療養所外での死亡・解剖の拒
否などにより, 病理解剖を実施できなかったものである。 この表にしめすように, 悪性腫瘍が33例にみられたが, その5ち 3 例の潜在性前立腺癌は主要死因とはならな い。小葉性肺炎（気管支肺炎）は67例にみられ, 主要死 因と考えられたのは54例であった。悪性腫瘍があって, おもな死因に小葉性肺炎もあげられたのは22例であっ た。これに反して，脳血管疾患による死亡と考えられる のは12例で，このうち5例は死因に連なる小葉性肺炎を 合併していた。往年の死因の第 1 位を占めていた結核に よる死亡は 8 例であり, 1966年から1969年に集中してい る。この中の 4 例は，これまであまり見られなかった乾 酪性大葉性肺炎であった5)。

Table 2 には, 剖検例の死亡年齢と, 悪性腫瘍, 脳血 管疾患の年齢層分布をしめした。入所者の老齢化はこの 表でも明らかである。当然のことながら，老齢者に小葉 性肺炎と悪性腫瘍の合併が多い。

大島青松園：1967年から1976年までに死亡した116名 を調查対象とした。この間の死亡数は1947 1956年の 218名, 1957 1966年の136名に比べて減少している。対 象例の病型別年齢構成を Table 3 にしめした。60歳台 の死亡者は全体の $31 \%$ をめている。Table 4 は厚生省 分類によって, これらの症例の死亡診断書および病歷か ら作製された死因別分類である。神経系とあるのが脳血 管疾患にあたり，循環系とあるのは現在の日本の死因第 3 位とされている心疾患である。悪性腫瘍は $12.1 \%$ とな 
Table 1 Main pathological findings of autopsy cases in Komyo-en Leprosarium

\begin{tabular}{|c|c|c|c|c|c|c|c|c|}
\hline \multirow{2}{*}{ Year } & \multirow{2}{*}{$\begin{array}{l}\text { No. of } \\
\text { the dead }\end{array}$} & \multirow{2}{*}{$\begin{array}{l}\text { Autopsy } \\
\text { cases }\end{array}$} & \multirow{2}{*}{$\begin{array}{l}\text { Malignant } \\
\text { neoplasm }\end{array}$} & \multicolumn{3}{|c|}{ Cerebrovascular disease } & \multirow[b]{2}{*}{$\begin{array}{c}\text { Active } \\
\text { tuberculosis }\end{array}$} & \multirow{2}{*}{$\begin{array}{l}\text { Bronchopn- } \\
\text { eumonia }\end{array}$} \\
\hline & & & & Hemorrhage & Softening & $\begin{array}{l}\text { Microscopic } \\
\text { hemorrhage }\end{array}$ & & \\
\hline 1962 & 16 & 15 & 3 & 0 & 0 & 0 & 0 & 8 \\
\hline 1963 & 9 & 7 & 0 & 1 & 0 & 0 & 0 & 5 \\
\hline 1964 & 12 & 12 & 5 & 0 & 1 & 0 & 0 & 9 \\
\hline 1965 & 8 & 8 & 4 & 0 & 0 & 2 & 0 & 6 \\
\hline 1966 & 11 & 10 & 3 & 0 & 0 & 0 & 2 & 4 \\
\hline 1967 & 16 & 14 & 2 & 3 & 2 & 1 & 1 & 10 \\
\hline 1968 & 17 & 15 & 5 & 2 & 0 & 3 & 3 & 8 \\
\hline 1969 & 14 & 13 & 5 & 1 & 0 & 3 & 2 & 9 \\
\hline 1970 & 21 & 13 & 5 & 2 & 0 & 2 & 0 & 7 \\
\hline $\begin{array}{c}1971 \\
(\mathrm{Jan} .\end{array}$ & $\begin{array}{r}3 \\
\text {-June) }\end{array}$ & 3 & 1 & 0 & 0 & 0 & 0 & 1 \\
\hline Total & 127 & 110 & 33 & 9 & 3 & 11 & 8 & 67 \\
\hline
\end{tabular}

Table 2 Relation of age to malignant neoplasms and cerebrovascular diseases in autopsy cases of Komyo-en Leprosarium

\begin{tabular}{cccc}
\hline \hline Age & Total & $\begin{array}{c}\text { Malignant } \\
\text { neoplasms }\end{array}$ & $\begin{array}{c}\text { Cerebrovascular } \\
\text { diseases }\end{array}$ \\
\hline $20-29$ & 1 & 0 & 0 \\
$30-39$ & 4 & 0 & 0 \\
$40-49$ & 13 & 3 & 2 \\
$50-59$ & 27 & 6 & 9 \\
$60-69$ & 28 & 10 & 6 \\
$70-79$ & 23 & 9 & 4 \\
$80-89$ & 14 & 5 & 1 \\
\hline
\end{tabular}

Table 3 Age and type of leprosy in cases of Seisho-en Leprosarium (1967-1976)

\begin{tabular}{cccccc}
\hline \hline \multirow{2}{*}{ Age } & \multicolumn{2}{c}{ Lepromatous } & \multicolumn{2}{c}{ Tuberculoid } & Total \\
& Male & Female & Male & Female & \\
\hline $30-39$ & 0 & 1 & 0 & 0 & 1 \\
$40-49$ & 7 & 3 & 0 & 2 & 12 \\
$50-59$ & 12 & 4 & 3 & 0 & 19 \\
$60-69$ & 19 & 8 & 6 & 3 & 36 \\
$70-79$ & 19 & 2 & 6 & 4 & 31 \\
$80-89$ & 3 & 4 & 4 & 3 & 14 \\
90 & 1 & 2 & 0 & 0 & 3 \\
Total & 61 & 24 & 19 & 12 & 116 \\
\hline
\end{tabular}

Table 4 Causes of death in cases of Seisho-en Leprosarium

\begin{tabular}{lccccc}
\hline \multirow{2}{*}{ Cause of death } & \multicolumn{2}{c}{ Lepromatous } & \multicolumn{2}{c}{ Tuberculoid } & Total \\
& Male & Female & Male & Female & \\
\hline Infectious disease & 7 & 3 & 0 & 0 & $10(8.6 \%)$ \\
Neoplasm & 6 & 6 & 1 & 1 & $14(12.1 \%)$ \\
Allergy & 3 & 0 & 0 & 0 & $3(2.6 \%)$ \\
Disease of nervous system & 6 & 4 & 4 & 3 & $17(14.7 \%)$ \\
Disease of circulatory system & 2 & 0 & 1 & 0 & $3(2.6 \%)$ \\
Disease of respiratory system & 15 & 5 & 5 & 3 & $28(24.2 \%)$ \\
Disease of alimentary system & 10 & 1 & 2 & 0 & $13(11.2 \%)$ \\
Disease of urogenital system & 2 & 1 & 0 & 0 & $3(2.6 \%)$ \\
Death due to senility & 7 & 3 & 3 & 3 & $16(13.8 \%)$ \\
Accident & 4 & 1 & 2 & 2 & $9(7.7 \%)$ \\
\hline
\end{tabular}

This table is based on the death certificates in the Leprosarium which are written according to classification of cause of death by the Ministry of health and Welfare. Cerebrovascular diseases are involved in "Diseases of nervous system". 
Table 5 Leading causes of death in Japan (1975)

\begin{tabular}{|c|c|c|c|c|c|}
\hline \multicolumn{6}{|c|}{ Cause of death } \\
\hline Age & $1 \mathrm{st}$ & $2 \mathrm{nd}$ & $3 r d$ & 4 th & 5 th \\
\hline $30-34$ & $\begin{array}{l}\text { Malignant } \\
\text { neoplasms }\end{array}$ & Suicides & Accidents & Heart diseases & $\begin{array}{l}\text { Cerebrovascular } \\
\text { diseases }\end{array}$ \\
\hline $35-39$ & $\begin{array}{l}\text { Malignant } \\
\text { neoplasms }\end{array}$ & Accidents & Suicides & Heart diseases & $\begin{array}{l}\text { Cerebrovascular } \\
\text { diseases }\end{array}$ \\
\hline $40-44$ & $\begin{array}{l}\text { Malignant } \\
\text { neoplasms }\end{array}$ & $\begin{array}{l}\text { Cerebrovascular } \\
\text { diseases }\end{array}$ & Accidents & Heart diseases & Suicides \\
\hline $45-49$ & $\begin{array}{l}\text { Malignant } \\
\text { neoplasms }\end{array}$ & $\begin{array}{l}\text { Cerebrovascular } \\
\text { diseases }\end{array}$ & Heart diseases & Accidents & Liver cirrhosis \\
\hline $50-54$ & $\begin{array}{l}\text { Malignant } \\
\text { neoplasms }\end{array}$ & $\begin{array}{l}\text { Cerebrovascular } \\
\text { diseases }\end{array}$ & Heart diseases & Accidents & Liver cirrhosis \\
\hline $55-59$ & $\begin{array}{l}\text { Malignant } \\
\text { neoplasms }\end{array}$ & $\begin{array}{l}\text { Cerebrovascular } \\
\text { diseases }\end{array}$ & Heart diseases & Accidents & Liver cirrhosis \\
\hline $60-64$ & $\begin{array}{l}\text { Malignant } \\
\text { neoplasms }\end{array}$ & $\begin{array}{l}\text { Cerebrovascular } \\
\text { diseases }\end{array}$ & Heart diseases & Accidents & Liver cirrhosis \\
\hline $65-69$ & $\begin{array}{l}\text { Malignant } \\
\text { neoplasms }\end{array}$ & $\begin{array}{l}\text { Cerebrovascular } \\
\text { diseases }\end{array}$ & Heart diseases & $\begin{array}{l}\text { Pneumonia and } \\
\text { bronchopneumonia }\end{array}$ & Accidents \\
\hline $70-74$ & $\begin{array}{l}\text { Cerebrovascular } \\
\text { diseases }\end{array}$ & $\begin{array}{l}\text { Malignant } \\
\text { neoplasms }\end{array}$ & Heart diseases & $\begin{array}{l}\text { Pneumonia and } \\
\text { bronchopneumonia }\end{array}$ & $\begin{array}{l}\text { Hypertensive } \\
\text { diseases }\end{array}$ \\
\hline $75-79$ & $\begin{array}{l}\text { Cerebrovascular } \\
\text { diseases }\end{array}$ & Heart diseases & $\begin{array}{l}\text { Malignant } \\
\text { neoplasms }\end{array}$ & $\begin{array}{l}\text { Pneumonia and } \\
\text { bronchopneumonia }\end{array}$ & $\begin{array}{l}\text { Hypertensive } \\
\text { diseases }\end{array}$ \\
\hline $80-$ & $\begin{array}{l}\text { Cerebrovascular } \\
\text { diseases }\end{array}$ & Heart diseases & Senility & $\begin{array}{l}\text { Pneumonia and } \\
\text { brodchopneumonia }\end{array}$ & $\begin{array}{l}\text { Malignant } \\
\text { neoplasms }\end{array}$ \\
\hline Total & $\begin{array}{l}\text { Cerebrovascular } \\
\text { diseases }\end{array}$ & $\begin{array}{l}\text { Malignant } \\
\text { neoplasms }\end{array}$ & Heart diseases & $\begin{array}{l}\text { Pneumonia and } \\
\text { bronchopneumonia }\end{array}$ & Accidents \\
\hline
\end{tabular}

This table is based on the annual report of the Ministry of Health and Welfare.

Table 6 Change of leading causes of death in Japan

\begin{tabular}{|c|c|c|c|c|c|}
\hline \multirow{2}{*}{ Year } & \multicolumn{5}{|c|}{ Cause of death } \\
\hline & $1 \mathrm{st}$ & 2 nd & 3 rd & 4 th & 5 th \\
\hline 1950 & Tuberculosis & $\begin{array}{l}\text { Cerebrovascular } \\
\text { diseases }\end{array}$ & $\begin{array}{l}\text { Pneumonia and } \\
\text { Bronchitis }\end{array}$ & Gastroenteritis & $\begin{array}{l}\text { Malignant } \\
\text { neoplasms }\end{array}$ \\
\hline 1951 & $\begin{array}{l}\text { Cerebrovascular } \\
\text { diseases }\end{array}$ & Tuberculosis & $\begin{array}{c}\text { Pneumonia and } \\
\text { Bronchitis }\end{array}$ & $\begin{array}{l}\text { Malignant } \\
\text { neoplasms }\end{array}$ & Senility \\
\hline 1956 & $\begin{array}{l}\text { Cerebrovascular } \\
\text { diseases }\end{array}$ & $\begin{array}{l}\text { Malignant } \\
\text { neoplasms }\end{array}$ & Senility & Heart diseases & Tuberculosis \\
\hline 1961 & $\begin{array}{l}\text { Cerebrovascular } \\
\text { diseases }\end{array}$ & $\begin{array}{l}\text { Malignant } \\
\text { neoplasms }\end{array}$ & Heart diseases & Senility & Accidents \\
\hline 1966 & $\begin{array}{l}\text { Cerebrovascular } \\
\text { diseases }\end{array}$ & $\begin{array}{l}\text { Malignant } \\
\text { neoplasms }\end{array}$ & Heart diseases & Senility & Accidents \\
\hline 1971 & $\begin{array}{l}\text { Cerebrovascular } \\
\text { diseases }\end{array}$ & $\begin{array}{l}\text { Malignant } \\
\text { neoplasms }\end{array}$ & Heart diseases & Accidents & Senility \\
\hline 1974 & $\begin{array}{l}\text { Cerebrovascular } \\
\text { diseases }\end{array}$ & $\begin{array}{l}\text { Malignant } \\
\text { neoplasms }\end{array}$ & Heart diseases & Accidents & $\begin{array}{c}\text { Pneumonia and } \\
\text { Bronchitis }\end{array}$ \\
\hline
\end{tabular}

This table is based on the report of the Ministry of Health and Welfare.

っており，最大の死因は呼吸器系の疾患 $(24.2 \%)$ であ

る。厚生省の統計では, 呼吸器系による死亡の順位は第 5 位となっている。

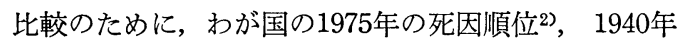
から1974年にいたる 死因順位の推移3)を Table 5，6に しめす。30歳台から60歳台の死因の第 1 位が悪性腫瘍で 
あることに注目したい。

\section{考察}

これら 2 つの療養所の死因調査の結果から, 脳血管疾 患は死因の第 1 位をしめるほど多くはないことを知らさ れる。死因の第 1 位は気管支肺炎を中心とする呼吸器系 疾患であり, 悪性腫瘍例の多くが末期に気管支肺炎を合 併して死亡している。青松園の例は病理解剖がなされて いないため，悪性腫場が $12.1 \%$ にとどまっているが，他 の死因の症例のなかに悪性腫瘍の例も含まれていること は充分推測される。したがって, 青松園の調查結果から みても, 覀性腫瘍は脳血管疾患より多いと考えてよいで あろう。

このように，瀬戸内海にある $2 つ の$ 療羑所の 10 年間の 死亡調査の結果は, わが国の主要死因の順位と異ってい る。国立京都病院では1976年に70例の剖検がおこなわ れ，そのうち64例が成人例であった。この64例のうち， 脳出血は 2 例, 脳軟化症は 1 例だったのに対して悪性腫 瘍は45例にのぼった。したがって, 今回の調査結果は 2 つの療養所に限られた特殊な状況によるものとはいえ ずむしろ，わが国の死亡統計に誤りがあることをしめ す所見であると考える。

最近, Netsky らは日本の脳出血・血栓症の発生状況 に関する論文を発表した6)。これによると，日本におけ る脳血管疾患, とくに脳出血の高い頻度は, 診断と記録 方法によって人工的につくり出されたものであると, き びしい批判がなされている。彼らは死因の第 1 位が悪性 腫瘍であり, 脳血管疾患は第 5 位か, それ以下の主要死 因であろらと記している。

では, なぜ脳血管疾患が日本人の死因第 1 位となって いるのだろうか。以下にその理由と推測されるものを挙 げて検討してみる。

1） 日本の死因統計は病理解剖によらず，死亡診断書 の記載によっているため。

わが国では剖検率が低く，報告された死因の内容が科 学的正確さに応えられるとはいえない面がある。

2）脳血管疾患のある患者は解剖されることがあまり ないため, 剖検例では少い。

わが国では, 脳血管疾患で長く臥床している人は病院 外で死亡することが多く, 解剖の機会は当然減少するこ とになる。
3）病理解剖される症例は悪性腫瘍の例が多いため。 剖検率のあまり高くない医療施設では充分考えられる ことである。しかし, 光明園の例では $86.6 \%$ の剖検率 で, 悪性腫瘍が脳血管疾患の約 3 倍あったということか ら，この理由の比重が低いことがわかる。

4) 日本人の死因では悪性腫陽が少いため。

これは，わたくしたちの身辺をかえりみても肯定でき ないことである。

以上をまとめれば，脳血管疾患が日本人の最大の死因 とされるのは，その統計の根拠となる記録に問題がある からといえよう。その誤りは, 病理解剖の重要さが, こ の国の医療人, 一般人にもっと認識されるまでは続くで あろら，と推測される。らい療養所の入所者と医療従事 者のために，今後も長期にわたって，なるべくすべての 症例について病理解剖が㧍こなわれ，その所見の整理が なされていくことを願っている。

\section{結 論}

邑久光明園，大島青松園における10年間といら期間を 通しての, 患者死亡の主要死因について検討した。病理 解剖診断がなされた光明園の場合, 主要死因の第 1 位は 悪性腫湟である。死亡診断書による青松園の死亡統計で も, 脳血管疾患は主要死因の第 1 位ではない。わが国で は脳血管疾患が死因の第 1 位であるという，1951年以来 の統計はおそらく誤りであろら。病理解剖の必要性を強 調した。

\section{文献}

1）厚生統計協会：厚生の指標一国民衛生の動向, 24, 9, 78-80 (1977).

2）厚生統計協会：厚生の指標一国民衛生の動向, 24, 9, 356-357 (1977).

3）厚生統計協会：厚生の指標一主要指標の年次推 移, 23, 16, 16-17 (1976).

4）尾崎元昭, 他：らい患者に続発する悪性腫瘍の 増加について一邑久光明園の剖検から一. 医療, 26, 517-522 (1972).

5）古田睦広, 他：病理解剖学にみた結核症一光明 園の剖検から一. 医療, 26, 139-144 (1972).

6) M. G. Netsky and T. Miyagi : Prevalence of cerebral hemorrhage and thrombosis in Japan, Study of the major causes of death. J. Chron. Dis., 29, 711-721 (1976). 